\title{
Computer-assisted reading intervention with a phonics approach for children using cochlear implants or hearing aids
}

\author{
Cecilia Nakeva von Mentzer, Björn Lyxell, Birgitta Sahlén, Örjan Dahlström, Magnus \\ Lindgren, Marianne Ors, Petter Kallioinen and Inger Uhlén
}

\section{Linköping University Post Print}

\section{Tweet}

N.B.: When citing this work, cite the original article.

Original Publication:

Cecilia Nakeva von Mentzer, Björn Lyxell, Birgitta Sahlén, Örjan Dahlström, Magnus Lindgren, Marianne Ors, Petter Kallioinen and Inger Uhlén, Computer-assisted reading intervention with a phonics approach for children using cochlear implants or hearing aids, 2014, Scandinavian Journal of Psychology, (55), 5, 448-455.

http://dx.doi.org/10.1111/sjop.12149

Copyright: Wiley: 24 months

http://eu.wiley.com/WileyCDA/

Postprint available at: Linköping University Electronic Press

http://urn.kb.se/resolve?urn=urn:nbn:se:liu:diva-108900 


\section{Abstract}

The present study examines computer-assisted reading intervention with a phonics approach for deaf and hard of hearing (DHH) children in Sweden using cochlear implants or hearing aids, or a combination of both. The study included forty-eight children, 5, 6 and 7 years of age. Sixteen children with normal hearing $(\mathrm{NH})$ served as a reference group. The first purpose of the study was to compare $\mathrm{NH}$ and DHH children's reading ability at pre and post intervention. The second purpose was to investigate effects of the intervention. Cognitive and demographic factors were analyzed in relation to reading improvement. Results showed no statistically significant difference for reading ability at the group level, although $\mathrm{NH}$ children showed overall higher reading scores at both test points. Age comparisons revealed a statistically significant higher reading ability in the NH 7-year olds compared to the DHH 7-year olds. The intervention proved successful for word decoding accuracy, passage comprehension and as a reduction of nonword decoding errors in both $\mathrm{NH}$ and $\mathrm{DHH}$ children. Reading improvement was associated with complex working memory and phonological processing skills in NH children. Correspondent associations were observed with visual working memory and letter knowledge in the DHH children. Age was the only demographic factor that was significantly correlated with reading improvement. The results suggest that DHH children's beginning reading may be influenced by visual strategies that might explain the reading delay in the older children.

Key words: children, deaf and hard of hearing, cochlear implants, hearing aids, computer-assisted reading intervention, phonics approach 


\section{Introduction}

Since the introduction of formal schooling in the Western world about 150 years ago (Edwards, 2012) a continuing pedagogical question has been how students who are deaf or hard of hearing (DHH) optimally develop reading ability. The different pedagogical practices and perspectives can broadly be divided into "whole language" versus "bottomup" approaches, i.e., to support semantic processing and prediction, or to support lexical as well as sub-lexical processing to develop reading (Power \& Leigh, 2000).

The heterogeneity within DHH children across a variety of domains, such as degree of hearing loss (HL), age at amplification, speech perception skills, communication mode, and educational placement, complicates the picture of how reading development is accomplished in this population (Easterbrooks \& Beal-Alvarez, 2012; Marschark, Rhoten, \& Fabich, 2007; Powell \& Wilson, 2011). Some studies report that subsets of DHH children are closing the gap to NH children, especially those in their younger school age who have been identified early, receive early auditory stimulation by means of a cochlear implant (CI), and are placed in educational settings among hearing peers (Easterbrooks \& Beal-Alvarez, 2012). Other studies state that $\mathrm{DHH}$ adolescents do not reach reading levels adequate for their age regardless degree of HL or whether they utilize CI (Marschark et al., 2007; Traxler, 2000), and that they are less accurate in monitoring their own comprehension, regardless of communication mode (Marschark et al., 2012). Thus, the diverse picture of how DHH children of different ages learn to read, and use reading to learn, makes it important to find methods that promote a good start into reading proficiency. One alternative way to address this issue is to offer reading intervention at home. The general purpose of the present study is to undertake computer-assisted reading intervention with a phonics approach in DHH children's homes. This has, according to our information, not been done before.

In skilled reading, language (i.e., phonological, morphological, semantic-syntactic and pragmatic competence) and visual processing (i.e., the formation of abstract letter and orthographic representations) are used flexibly to derive meaning from print (Bavelier, Green, \& Seidenberg, 2013; Bitan, Manor, Morocz, \& Karni, 2005; Bjaalid, Høien, \& Lundberg, 1997; Byrne et al., 2009; Castles et al., 2009; Rastle, 2007). Phonological decoding skills are essential when reading unfamiliar and low frequency words (Share, 1995) and orthographic decoding skills are important for sight-word reading which affects reading 
speed (Coltheart, Rastle, Perry, Langdon, \& Ziegler, 2001). As phonological decoding functions as a self-teaching mechanism it enables the learner to independently acquire an autonomous orthographic lexicon (Share, 1995). Therefore phonological decoding is relatively more important than orthographic decoding in beginning reading development. A challenge for both $\mathrm{CI}$ and hearing aid (HA) users in utilizing phonological decoding strategies is that the hearing loss (HL) itself prevents them to perceive the phonemes clearly. Lowered hearing thresholds in combination with reduced spectral and temporal information delivered through the hearing device, explain their lower perceptual precision (Bouton, Serniclaes, Bertoncini, \& Cole, 2012; Moore, 2008). Development of phonological knowledge however need not be limited to lower auditory perceptual mechanisms (Adams Jager, 2003) and might be compensated by other senses, i.e., visual (Woodhouse, Hickson, \& Dodd, 2009). The fundamental point is to consider the phonemes as a set of linguistic meaningless units out of which meaningful units are formed (Trezek \& Malmgren, 2005). Recent studies have shown altered reading strategies in DHH children (Lyxell et al., 2008; Wass et al., 2010). Children with CI have been observed to use visual skills and develop orthographic decoding strategies earlier, probably related to a more profound HL, compared to children with HA (Asker-Árnason, Wass, Gustavsson \& Sahlén, 2013). One point of departure in the present study is the question whether DHH children rely more on visual clues than $\mathrm{NH}$ children do in beginning reading development. Another question is whether DHH children's beginning reading is as highly influenced by lexical access skills, different aspects of working memory, and phonological processing skills as they are for NH children (Caravolas et al., 2012; Nevo \& Breznitz, 2011).

Previous research has shown that DHH children's letter-sound knowledge skills can be improved by means of computer-assisted intervention with a phonics approach (Nakeva von Mentzer et al., 2013). Further, the phonics approach has been observed effective for nonword and word reading accuracy as well as for letter-sound knowledge in NH poor readers (Hatcher, Hulme, \& Snowling, 2004; McArthur et al., 2012). To our knowledge, the effects of a computer-assisted phonics approach on DHH children's reading development has not been examined previously (Beal-Alvarez, Lederberg, \& Easterbrooks, 2012; Trezek \& Malmgren, 2005). In the present study a phonics approach which is implemented in a computer-assisted intervention program, is used to study the effects on reading development in DHH children (Lyytinen, Ronimus, Alanko, Poikkeus, \& Taanila, 2007). The study has 
three purposes. First, compare NH and DHH children's reading ability pre and post intervention. Second, examine effects of the intervention. Third, analyze how cognitive and demographic factors relate to reading improvement in $\mathrm{NH}$ vs. DHH children.

\section{Method and Material}

\section{Participants}

A total of forty-eight children participated in the present study. Written parental informed consent was obtained for all the participants. Participants were matched for age and nonverbal intelligence on a group level (Raven, 1995). The inclusion criteria for DHH were that they should have a mild, moderate to severe or profound bilateral sensorineural HL and be full time users of $\mathrm{CI}(\mathrm{s})$ or $\mathrm{HA}(\mathrm{s})$. The inclusion criterion for the reference group was normal hearing ascertained at the regular hearing screening at 4 years of age and reported by their parents in a written consent form. For more detailed information regarding the recruitment of participants see also Nakeva von Mentzer et al. (2013). The study was approved by the Regional Committee for Medical Research Ethics; Stockholm, Sweden.

Deaf and hard of hearing children. Seventeen of the children used CI(s) (11 bilateral CIs), and 15 used bilateral HAs. Nineteen of the children had a severe/profound HL with a Pure Tone Average (PTA) at $70 \mathrm{~dB}$ hearing level or more unaided. Eleven had a moderate HL and two had a mild HL. For the majority of children the cause of hearing impairment (HI) was hereditary or unknown. Cytomegalovirus (CMV) (1 child) and toxicological exposure ( 1 child) were the causes of the known non-hereditary HI. Half of the children were diagnosed before one year of age. The mean age at diagnosis for children with CIs was 11 months ( $S D=12$ months), and for children with HAs 2 years and 3 months ( $S D=26$ months). Seven children were diagnosed with a progressive HI. The mean age of receiving CI $(N=$ 11) was 1 year and 8 months and the mean age of receiving HA was 2 years and 8 months $(N=21$, bilateral HA and CI/HA). All children with CI were, as is routine in Sweden, fitted with bilateral conventional HAs after the diagnosis of HI. No child was receiving intervention at the time of the study, except regular technical controls at the Audiological clinic. For further information about the DHH children's communication mode see also 
Nakeva von Mentzer et al. (2013). For demographic variables and nonverbal intelligence scores, see Table 1.

Children with $\mathrm{NH}$. In the reference group of children with $\mathrm{NH}$ there was one bilingual child (proficient in Swedish and English).

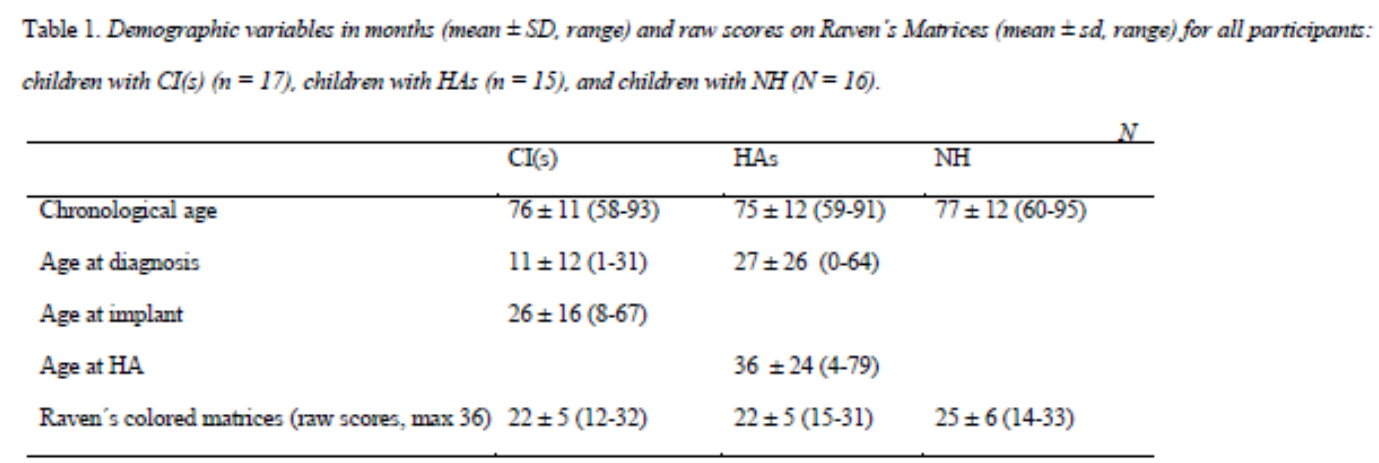

Note: $\mathrm{CI}=$ cochlear implants, $\mathrm{HA}=$ hearing aids, $\mathrm{NH}=$ normal hearing

Procedure

All participants were tested by a Speech Language Pathologist (SLP) with broad experience of testing children. The test procedure included three sessions; 1) baseline 1, 2) pre intervention, and 3) post intervention with four weeks in between. Eight tests for phonological processing skills and letter knowledge were assessed at all three test points. These results are reported in a previous study where an extensive description of the test procedure is given (Nakeva von Mentzer et al., 2013). Sessions pre and post intervention included tests for visual and complex working memory and reading described below. The duration of sessions at pre and post intervention was approximately 90 minutes. Children were given one pause after completing half of the tests. Instructions were presented orally for all but two DHH children who used sign as their main communication mode at home. A sign language interpreter was used in these two cases. With the use of a sign interpreter the duration of the test session was slightly prolonged. Comfortable presentation level and audition were secured by first asking the child and the parent whether the HA or CI was working properly. Second, the child was asked to listen and tell what he/she heard from two initial sentences in the Sentence Repetition task presented from two external loudspeakers 
(SIPS; Wass et al., 2008). The presentation level was adjusted according to the child's answer, i.e., when a child expressed that he/she found it hard to hear, the volume was increased to ensure a comfortable audible level for each individual child. For information about the tests analyzed in the present study see Table 2 . 
Table 2. Tests administered

\begin{tabular}{|c|c|c|}
\hline Area & Test & Quantification \\
\hline Nonverbalintelligence & Raven's colored matrices & Number of correct answers $(\max =36)$ \\
\hline \multirow{4}{*}{ Phonological coding } & $\begin{array}{l}\text { Lower-case letter names - pointing (Clay, } \\
\qquad 1975 \text { ) }\end{array}$ & Number of correct answers $(\max =26)$ \\
\hline & Lower-case letter sounds - pointing (Clay, & Number of correct answers $(\max =26)$ \\
\hline & 1975) & \\
\hline & $\begin{array}{l}\text { Lower-case letter sounds- naming } \\
\qquad \text { (Frylmark, 1995) }\end{array}$ & Number of correct answers ( $\max =24$ ) \\
\hline Lexical access & $\begin{array}{l}\text { Sentence completion and recall, SCR } \\
\text { (SIPS, Wass et al., 2008) }\end{array}$ & $\begin{array}{l}\text { Total number of correctly completed sentences } \\
\qquad(\max =18)\end{array}$ \\
\hline Complex working memory & $\begin{array}{l}\text { Sentence completion and recall, SCR } \\
\text { (SIPS, Wass et al., 2008) }\end{array}$ & Total number of conrectly recalled words \\
\hline Visual working memory & Visual matrix (SIPS, Wass et al., 2008) & $\begin{array}{l}\text { Total number of correctly reproduced test pattems (two } \\
\text { out of three test patterns at the highest difficulty level, } \\
\qquad \max =8 \text { ). }\end{array}$ \\
\hline \multirow{7}{*}{ Phonological processing skills } & Phoneme test (Hellqvist, 1995) & $\begin{array}{l}\text { Percent consonants correct out of } 207 \text {; dialect midst of } \\
\text { Sweden, or } 211 \text {; dialect south of Sweden (pcc) }{ }^{1} \\
\text { Percent words correct out of } 72 \text { (pwc) }\end{array}$ \\
\hline & $\begin{array}{l}\text { Nonword repetition, (SIPS, Wass et al., } \\
\text { 2008) }\end{array}$ & $\begin{array}{l}\text { Percent nonwords out of } 24(\mathrm{pnwc})^{1} \\
\text { Percent consonants out of } 120(\mathrm{pcc})^{1}\end{array}$ \\
\hline & $\begin{array}{l}\text { Phonological representations, (SIPS, Wass } \\
\text { et al., 2008) }\end{array}$ & $\begin{array}{l}\text { Percent correct responses }{ }^{1} \\
\qquad(\max =18)\end{array}$ \\
\hline & $\begin{array}{l}\text { Nonword discrimination accuracy and } \\
\text { latency for correct responses, (SIPS, Wass }\end{array}$ & $\begin{array}{l}\text { Percent correctly discriminated pairs of nonwords }{ }^{1} \\
\qquad(\max =8)\end{array}$ \\
\hline & et al., 2008) & Mean response latency (ms) \\
\hline & $\begin{array}{l}\text { Phoneme Identification accuracy and } \\
\text { latency, (SIPS, Wass et al., 2008) }\end{array}$ & $\begin{array}{l}\text { Percent correctly identified phonemes }{ }^{1} \\
\qquad(\max =12)\end{array}$ \\
\hline & & Mean response latency (ms) \\
\hline \multirow[b]{4}{*}{$\begin{array}{c}\text { Reading } \\
\text { comprehension }\end{array}$} & $\begin{array}{l}\text { Test of word reading efficiency (TOWRE; } \\
\text { Torgesen, Wagner \& Rashotte, 1999, } \\
\text { Swedish version by Byme et al., 2009) }\end{array}$ & $\begin{array}{l}\text { Number of correctly decoded words. } \\
\qquad(\max =208)\end{array}$ \\
\hline & & $\begin{array}{l}\text { Number of correctly decoded nonwords in } 2 \times 45 \mathrm{~s} \text {. } \\
\qquad(\max =126)\end{array}$ \\
\hline & & $\begin{array}{l}\text { Number of totally decoded words and nonwords }{ }^{2} \\
\qquad(\max =334)\end{array}$ \\
\hline & $\begin{array}{l}\text { Woodcock reading mastery test-Revised } \\
\text { (Woodcock } 1987 \text {; Swedish version by } \\
\text { Byme et al. 2009) }\end{array}$ & $\begin{array}{l}\text { Number of semantically correct answers }{ }^{2} . \\
\qquad(\max =68)\end{array}$ \\
\hline
\end{tabular}

Notes: SIPS=Sound Information Processing System (Wass et al., 2008), pcc = percent consonants correct, pwc $=$ percent words correct, pnwc $=$ percent words correct, ${ }^{1}$ Subtests combined to produce the phonological composite score, ${ }^{2}$ Subtests combined to produce the reading composite score

Tests

Tests were presented via paper (Letter naming; Frylmark, 1995; TOWRE; Torgesen, Wagner \& Rashotte, 1999, Swedish version by Byrne et al., 2009; Woodcock Reading Mastery test- 
Revised, 1987; Swedish version by Byrne et al., 2009) and cards (Letter knowledge; Clay, 1975), as well as by computer with a cognitive test battery called the SIPS, the Sound Information Processing System (Wass et al., 2008). The SIPS has been developed from three theoretical paradigms; the Working memory model (Baddeley, 2012; Baddeley \& Hitch, 1974), the Capacity theory (Just \& Carpenter, 1992), and theories within specific language impairment (Bishop, 1997; Gerken, 1994; Kamhi \& Catts, 1986; Leonard, 1998; Sahlén, Reuterskiöld-Wagner, Nettelbladt, \& Radeborg, 1999). A brief description of the tests is given below. For an extensive description of the tests and procedures from the SIPS see Wass et al. (2008) and for tests of phonological processing skills and phonological coding see Nakeva von Mentzer et al. (2013).

Two letter recognition tasks were used to measure phonological coding of lower case letters from names or sounds (Clay, 1975). Maximum score was 26.

A letter-naming task was used to measure phonological coding in naming of lower case letters (Frylmark, 1995). The maximum score was 24.

The Sentence Completion and Recall task, SCR (SIPS; Wass et al., 2008) was used for two purposes, to assess complex working memory (below) and lexical access. Children received one point for each semantically acceptable filled-in word. Maximum score was 18.

The SCR task (SIPS; Wass et al., 2008) was used to assess complex working memory, i.e., the capacity to simultaneously store and process information (Just \& Carpenter, 1992; Repovš \& Baddeley, 2006). The results were scored as the total number of correctly stored and reproduced words, with a maximum score of 18 .

The Visual Matrix test (SIPS; Wass et al., 2008) was used to assess visual working memory (Baddeley, 2003). The children received scores for the highest level of difficulty at which they correctly reproduced two out of three test patterns. Maximum score was 8 .

A Phonological Composite Score was created in order to increase the sensitivity and strength of seven specific phonological processing measures, and to enable a general comparison of 
the children (Nakeva von Mentzer et al., 2013). The phonological composite score was calculated by a unit weighted-procedure, i.e., each unit was calculated in percent accurate, and then summarized to a global score. Seven units from five tasks of phonological processing skills constituted the phonological composite score, these are described in detail in Wass et al. (2008) and Nakeva von Mentzer et al. (2013). Items were; 1. Nonword repetition (percent nonwords correct; pnwc), 2. Nonword repetition (percent consonants correct; pcc), 3. Phoneme test (percent words correct; pwc) 4. Phoneme test (pcc), 5. Phonological Representations, 6. Nonword Discrimination, and 7. Phoneme Identification. Pearson's correlation coefficient showed moderate to strong correlations between normally distributed units (Nonword Repetition, pcc, Nonword Discrimination, and Phoneme Identification; $r=.50-r=.74, p<.01$ for all correlations) as well as moderate to strong correlations between units violating assumptions of normality as tested by Kendall's Taub's correlation coefficient (Phonological representations, Nonword Repetition, pnwc, Phoneme-test, pwc and pcc; $r=.51-.91, p<.01$ for all correlations), suggesting they measure a similar construct.

The Test of Word Reading Efficiency (TOWRE; Torgesen, Wagner \& Rashotte, 1999, Swedish version by Byrne et al., 2009) was used to assess orthographic and phonological decoding. The child was required to read aloud as many words/nonwords as possible in 45 s. He/she was also asked to read as correctly as possible. This procedure was repeated twice with two separate lists of words/nonwords. Children's performance was audio-recorded. Word and nonword decoding was scored in two ways;

1) Reading accuracy. The children received credits for every word/nonword read correctly (maximum score 208/126). The total decoding score for both words and nonwords was 334 .

2) Decoding errors. The children's decoding errors were calculated as percent incorrectly decoded words/nonwords of the total sum of read words/nonwords (correct and incorrect). Total percent incorrectly decoded words/nonwords were used as outcome measure. Children who read at least one word/nonword correct on TOWRE at pre intervention were included. Children with knowledge in phoneme-grapheme correspondence but did not blend sounds into words were excluded. 
The Woodcock Passage Comprehension Test (Woodcock 1987; Swedish version by Byrne et al., 2009) was used to assess reading comprehension. This test uses a cloze procedure to assess the child's ability to understand passages of connected text. The children's semantically accepted answers were scored. The maximum score was 68 .

A Reading Composite Score was calculated as the summary in percent of the total decodingscore of TOWRE and the passage comprehension-score of Woodcock. This was completed pre and post intervention.

Reading change was calculated as the difference in three respective scores (word decoding, nonword decoding, and passage comprehension) between post and pre intervention.

Group comparisons pre intervention did not reveal any significant difference between $\mathrm{NH}$ and DHH children's reading level. Age group comparisons showed that the NH 7-year old children started out at a significantly higher level than the DHH 7-year olds. There were strong correlations (Kendall's tau-b) between TOWRE (total decoding score) and Woodcock, passage comprehension-score pre intervention, $(r=.94, p<.001)$, suggesting that these tests measure a common underlying skill in children aged 5-7 years.

\section{Inter-rater reliability}

Transcriptions followed the same procedure that has been used in similar studies using the same test items for nonword repetition (Wass et al., 2008, Ibertsson et al., 2009). Inter-rater reliability was measured on 15 percent of the collected data for transcriptions on the Nonword Repetition task at baseline 1 (percent nonwords correct and percent consonants correct; pcc) and the picture-naming task (pwc and pcc). This was accomplished with Pearson's correlation coefficient between the first author and two SLPs. The inter-rater reliability between the three SLPs was at least $r=.828(p<.01)$.

Intervention program and setting

The intervention was accomplished by a Swedish version of a computer-assisted program that focused on training of phonological coding at letter, syllable (mono-syllabic words) and word level (Brem et al., 2010; Lyytinen, Erskine, Kujala, Ojanen, \& Richardson, 2009; Specialpedagogic 
Center, Vasa, 2006-2008) The intervention program provides highly repetitive and individualized intervention in which the child matches auditory targets (phonemes or spoken words) with visual targets (graphemes or written words). The Swedish version included 56 levels, categorized in three themes according to the phonological and orthographical complexity of the words. It started with isolated capital letters and their corresponding sounds, then introduced the lower case letters, advanced to one-syllable words with CV (consonant vowel) structure (theme 1), proceeded to VC, CVC, VCC and CVCC structures (theme 2), and finally delivered training for up to seven letter words (theme 3 ). The words at theme 3 contained initial consonant clusters as well as words with the first examples of larger grapho-phonemic units, namely the bi-graphs "ng" [n], "sj" [S] and tj [ç]. Children's response accuracy was rewarded continuously through the game and varied backgrounds and formats were used. After each level of difficulty the child was rewarded with tokens presented in another background, i.e., a castle or a garden. For an extensive description of the intervention program see also Kyle, Kujala, Richardson, Lyytinen \& Goswami (2013). Mean time of daily practice was 7 minutes and total mean time of practice was 202 minutes (SD = 52, 85 - 334). Group comparisons (NH, DHH) of the mean score of total amount of playing, reached levels in the game, or percent mean correct during practice showed no significant difference (Nakeva von Mentzer et al., 2013).

Design and statistical analyses

Reported data are from pre and post intervention. A Mann-Whitney U test was used for group and age comparisons at both test points. A paired samples t-test was conducted to analyze improvement in reading accuracy (words, nonwords and passage comprehension) from pre to post intervention in NH children. Wilcoxon Signed Rank Test was chosen as the nonparametric alternative for DHH children. Mixed design ANOVA was used to analyze differences in decoding errors (percent words and nonwords decoded incorrectly) with time as within-group factor (from pre to post intervention) and children's hearing status as between-group factor (2 groups; $\mathrm{NH}$ and $\mathrm{DHH}$ ). Only children who were judged as readers at pre intervention (NH: $n=12$, DHH: $n=19$ ) were included (see Method section).

Following this, correlations (Kendall's Tau-b; NH: $N=16$; DHH: $N=32$ ) were calculated between reading change-scores (see Method section) and all measures obtained pre intervention as well as between reading change-scores and demographic variables. 
Results

Results for decoding accuracy and passage comprehension are presented first, followed by decoding errors, reading change, and the correlation analysis.

\section{Group comparisons}

Word/nonword decoding accuracy and passage comprehension. Table 3 displays the mean, $S D$, and range for decoding accuracy and passage comprehension in percent at pre and post intervention at the group level for children with $\mathrm{NH}(N=16)$ and DHH children $(N=32)$. There was a tendency towards overall higher scores at both test points for the NH children but no statistically significant difference was observed. Largest differences were observed for percent nonword decoding accuracy (pre intervention; $\mathrm{NH}=12.0, \mathrm{DHH}=7.1$ ) and passage comprehension $(\mathrm{NH}=13.2, \mathrm{DHH}=8.0)$. Age comparisons revealed statistically significant higher reading scores only for the $\mathrm{NH} 7$-year old children compared to the DHH 7-year old children at both test points (e.g. pre intervention nonword decoding; $z=-2.64$ ).

\section{Intervention effects}

Word/nonword decoding accuracy and passage comprehension. For NH children there was a statistically significant gain between pre and post intervention for all measures of reading ability; percent word decoding accuracy (pre; $M=9.8, S D=13.1$, post; $M=13.3, S D=$ $16.1), t(15)=-.3 .24, p<.01$ ), nonword decoding accuracy (pre; $M=12.0, S D=13.8$, post; $M=14.1, S D=14.1), t(15)=-.2 .83, p<.01$ ), passage comprehension (pre; $M=13.2, S D=$ 18.5 , post; $M=18.8, S D=15), t(15)=-3.49, p<.01$, and for the reading composite score (pre; $M=11.8, S D=15.1$, post $M=15.3, S D=16.8$ ), $t(15)=-.4 .39, p<.01$. Statistically significant gain was observed for DHH children in word decoding accuracy, $z=-3.06, p<$ .01 , passage comprehension, $z=-2.94, p<.01$, and for the reading composite score, $z=-$ $3.06, p<.01$. 


\begin{tabular}{|c|c|c|c|c|}
\hline & \multicolumn{2}{|c|}{$\mathrm{NH}$} & \multicolumn{2}{|c|}{$\mathrm{DHH}$} \\
\hline & Pro & Post & Pro & Post \\
\hline \multicolumn{5}{|l|}{ Decoding accuracy } \\
\hline TOWRE - wordas b & $9.8=13.1(0-36)$ & $13.3=16.1(0-48)^{*}$ & $7.3 \pm 10.9(0-47)$ & $9.6 \pm 12.7(0-53)^{*}$ \\
\hline TOWRF - nonwords ${ }^{2 b}$ & $12.0=13.8(0-39)$ & $14.1=14.1(0-41)^{*}$ & $7.1 \pm 10.5(0-49)$ & $9.3 \pm 11.8(0-54)$ \\
\hline \multicolumn{5}{|l|}{ Passage comprohension } \\
\hline Woodcock (semantically corroct) & $13.2=18.5(0-49)$ & $18.8=21.7(0-51)^{*}$ & $8.0 \pm 11.9(0-38)$ & $10.4 \pm 13.6(0-37)^{*}$ \\
\hline Resding counposite rcore" & $11.8=15.1(0-39)$ & $15.3=16.8(0-47)^{*}$ & $7.5=10.9(0-45)$ & $9.7 \pm 12.2(0-47)^{*}$ \\
\hline
\end{tabular}

Note: $\mathrm{NH}=$ normal hesring, $\mathrm{DHH}=$ deaf and hard of hesring, "teets combined to produce the resding coumpocite score, bistribution violated the assumption of normslity in DHH childron, "a statistically significant difference from pre to port intervention was obeervod. $p=05$.

Word and nonword decoding errors. Thirty-one children classified as readers at pre intervention were included in the analysis of decoding errors. The mean age of the reading children was 81 months. There was no significant age difference between the groups, $t(29)$ $=0.43, p=.63(\mathrm{NH}$; mean 82 months, range 61-97, $n=12$ vs. DHH; mean 80 months, range $58-93, n=19)$. Mixed design ANOVA showed a significant reduction on percent word and nonword decoding errors, $F(1,29)=8.18, p=.008, \eta 2=.03$. The result was due reduction of nonword decoding errors at post intervention $F(1,29)=5.73, p=.023, \eta^{2}=.04$, while there was no significant reduction on percent word decoding errors, $F(1,27)=0.53, p=.47$. No significant effect of children's hearing status was observed in any analysis, but mean scores revealed a higher proportion of nonword decoding errors in DHH children (Table 4). There were no interactions between time (from pre to post intervention) and hearing status. 
Table 4. Decoding errors in percent (mean; $\pm s d$, range) in reading children pre and post intervention $(N H, n=12$, DHH, $n=19)$

\begin{tabular}{lccccc}
\hline & & NH & & DHH \\
\cline { 2 - 5 } & & Pre & Post & Pre & Post \\
\hline TOWRE - words & $28^{a} \pm 21.2(1-60)$ & $33 \pm 24.4(6-88)$ & $41 \pm 27.0(5-100)$ & $36 \pm 21.6(7-73)$ \\
TOWRE-nonwords & $43 \pm 27.6(4-100)$ & $33 \pm 13.7(12-59)^{*}$ & $54 \pm 26.0(20-100)$ & $46 \pm 24.0(5-85)^{*}$ \\
TOWRE - words and nonwords & $40 \pm 26.0(7-83)$ & $31 \pm 15.0(11-58)^{*}$ & $47 \pm 24.9(19-87)$ & $40 \pm 21.4(13-75)^{*}$ \\
\hline
\end{tabular}

Note $: \mathrm{NH}=$ normal hearing, $\mathrm{DHH}=$ deaf and hard of hearing, ${ }^{a} n=10$, *a statistically significant difference from pre to post intervention was observed, $p<.05$

Reading change. Largest changes were observed in the passage comprehension changescores for both NH and DHH children (see Table 5).

Correlation analysis

Correlations are presented in Table 6 . In the NH children reading change was most strongly associated with complex working memory, the phonological composite score and letter knowledge. In the DHH children reading change was most strongly associated with letter knowledge and visual working memory. Age was the single demographic variable significantly correlated with reading change in both groups. 
Table 5. Reading change-scores in percent (mean, \pm sd, range) at post intervention for $N H(N=16)$ and DHH children $(N=32)$.

\begin{tabular}{lll}
\hline & $\mathrm{NH}$ & DHH \\
\hline Word decoding change-score & $3.5 \pm 4.3(0-14)^{*}$ & $2.2 \pm 2.7(-1-10)^{*}$ \\
Nonword decoding change-score & $2.2 \pm 3.1(-2-10)^{*}$ & $2.2 \pm 2.7(-3-7)$ \\
Passage comprehension change-score & $5.6 \pm 6.4(0-18)^{*}$ & $2.4 \pm 5.5(-4-21)^{*}$ \\
Reading composite change-score & $3.8 \pm 3.0(0-8)^{*}$ & $2.3 \pm 2.8(-1-10)^{*}$ \\
\hline
\end{tabular}

Note $: \mathrm{NH}=$ normal hearing, $\mathrm{DHH}=$ deaf and hard of hearing, *change scores that were statistically significant, $p<.05$.

Table 6. Correlation analysis for word docoding, nonword docoding, and reading comprehension change-scores for $N H(N=16)$ and $D H H$ chiladren $(N=32)$.

\begin{tabular}{|c|c|c|c|c|c|c|}
\hline & \multicolumn{2}{|c|}{ Word decoding change-score } & \multicolumn{2}{|c|}{ Nonword decoding chrmgo-score } & \multicolumn{2}{|c|}{ Resding courprohension change-score } \\
\hline & $\mathrm{NH}$ & $\mathrm{DHF}$ & $\mathrm{NH}$ & $\mathrm{DHF}$ & $\mathrm{NH}$ & $\mathrm{DHH}$ \\
\hline Phonological composito-rcoro & $.52^{*}$ & .20 & .21 & .12 & $.42^{*}$ & .15 \\
\hline Lexical access- sentence coumpletion & .21 & .15 & -.04 & -.05 & .26 & .16 \\
\hline Complex working memory & $.69 * *$ & $.32^{*}$ & .14 & .09 & .38 & .23 \\
\hline Visual wothing memory & .18 & $.47^{* *}$ & -.01 & $.30^{*}$ & -.11 & .12 \\
\hline Phonological coding-letter sounds & .24 & $.53 * *$ & -.12 & .27 & $.49 *$ & .26 \\
\hline Phonological coding-lettor numes & .18 & $.38 * *$ & .02 & .13 & .40 & .25 \\
\hline Phonological coding-letter naming & 36 & $.52 * *$ & .07 & $.29^{*}$ & .44 & .26 \\
\hline Non twrbal intelligence - raw scores & .18 & $.37^{*}$ & .18 & $.34^{*}$ & .07 & -10 \\
\hline Age at $\mathrm{CI}$ & & -.17 & & -.26 & & -38 \\
\hline Age at $H A$ & & .26 & & .01 & & -13 \\
\hline Gender & .21 & -.01 & .30 & -.19 & .17 & .06 \\
\hline Ago at pro intervoution & $.57 * 4$ & $.36 * *$ & .05 & .16 & $.51^{*}$ & .15 \\
\hline
\end{tabular}

Note: $\mathrm{NH}=$ nornal hearing. $\mathrm{DHH}=$ deaf and hard of hearing. $\mathrm{CI}=$ cochlear implants, $\mathrm{HA}=$ hearing aids. ${ }^{*} p<.05,{ }^{* *} p<.01$

\section{Discussion}

The first purpose of the study was to compare NH and DHH children's reading ability at pre and post intervention. Second, effects of the intervention were examined. Results showed that children with $\mathrm{NH}$ had overall higher reading scores at both test points, although only statistically significant for the 7-year olds. The intervention proved successful for both 
$\mathrm{NH}$ and DHH children on the majority of reading measures. A slightly different trajectory was observed in nonword decoding accuracy where only NH children improved their skills. On the other hand there was a significant reduction in the proportion of nonword decoding errors for all children. These results support the notion that offering a computer-assisted intervention program delivered at home, is an alternative way to support not only $\mathrm{NH}$ children with reading difficulties (Saine, Lerkkanen, Ahonen, Tolvanen, \& Lyytinen, 2011) but also DHH children in developing, above all, phonological decoding proficiency. The novelty of the present study was that it has compared word and nonword decoding-errors in $\mathrm{NH}$ and DHH children and put this in relation to a phonics approach, implemented in a computer-based program. This has, to our knowledge, not been done before. Although not significant, there was a tendency towards a larger proportion of nonword decoding errors in DHH children at both points in time, suggesting that they find this task relatively more difficult than the NH children.

The third purpose was to examine the relation between the three different reading change-scores, cognitive and demographic variables in the children. The results showed a different pattern for $\mathrm{NH}$ and $\mathrm{DHH}$ children. In NH children the word decoding change-score showed significant correlations with complex working memory, phonological processing skills and age. This suggests a combined influence of domain general variables and phonological processing skills in word decoding development for the $\mathrm{NH}$ children in the present study. The importance of phonological processing skills, and particularly phonological working memory in early word recognition development, has been acknowledged in other studies within the field (Caravolas et al., 2012; Melby-Lervåg, Lyster, \& Hulme, 2012). Further, in a study by Nevo and Breznitz (2011) the influential role of complex working memory in early reading achievement has been recognized. Nevo and Breznitz concluded that adding measures of complex working memory might contribute significantly in predicting children's academic success. For DHH children two out of three reading change-scores were associated with visual working memory and letter knowledge. This corroborates the findings in the study by Asker-Árnason et al. (2013) where visual working memory was positively and significantly correlated with passage comprehension for the CI-users. The finding that letter knowledge was strongly correlated with the word and nonword decoding change-score stresses the importance of establishing firm visual 
symbols when learning to decode both in NH and DHH children (Caravolas et al., 2012; Kyle \& Harris, 2011; Lervåg, Bråten \& Hulme, 2009; Lyytinen et al., 2007).

Reading is often viewed as the ability to flexibly use both phonological and orthographic decoding, and preferably in that order for the beginning reader (Nation, Allen, \& Hulme, 2001). The results from the present study raised questions regarding DHH children's beginning reading strategies. Firstly, there were no significant correlations between reading improvement and phonological processing skills. Secondly, a tendency towards more nonword decoding errors was observed. Thirdly, there was no gain of the intervention in nonword decoding accuracy in the DHH children. If the DHH child solely uses the salient features within the word to find visual patterns, and does not use phonological processing skills, this might have negative consequences for decoding accuracy (Foorman \& Liberman, 1989; Frith, 1985; Share, 1995). Consequently, the DHH children might not develop the self-teaching mechanisms enabling them to independently acquire an autonomous orthographic lexicon (Share, 1995). An alternative interpretation might be that if DHH children develop phonological processing as a consequence of learning to read, as some studies indicate (Colin, Magnan, Ecalle, \& Leybaert, 2007; Kyle \& Harris, 2010) their reading strategies might change towards more use of phonological processing skills as they become more proficient readers. Age was the only demographic factor that turned out to be significantly correlated with the reading change-scores. 


\section{Conclusions}

Both $\mathrm{NH}$ and $\mathrm{DHH}$ children improved their reading ability after four weeks of computer-assisted intervention with a phonics approach. Thus, home-based reading intervention that focused on the connection between phonemic sounds and their visual counterparts was beneficial for this group of DHH children. Significantly higher reading scores were observed in the NH 7-year old children compared to the DHH 7-year old children, suggesting a beginning reading delay in the latter group. The DHH children's reading development (reading change-scores) was associated with visual working memory and letter knowledge, whereas for the $\mathrm{NH}$ children with complex working memory and phonological processing skills. The correlation between reading change and visual working memory suggests that DHH beginning reader's use visually based reading strategies. This may explain the lagging behind in reading development for the older DHH children in the present study.

\section{References}

Adams Jager, M. (2003). Beginning to read: Thinking and Learning about Print. A Bradford book, MIT Press, United States of America

Asker-Árnason, L., Wass, M., Gustavsson, F., \& Sahlén, B. (submitted Volta Review, 2014). Reading comprehension and working memory in children with hearing impairment and cochlear implants and hearing aids.

Baddeley, A. (2003). Working memory and language: An overview. Journal of Communication Disorders, 36(189-208).

Baddeley, A. (2012). Working memory: Theories, models, and controversies. Annual review of psychology, 63, 1-29. doi: 10.1146/annurev-psych-120710-100422

Baddeley, A.D., \& Hitch, G. (1974). Working memory. In G.H. Bower (Ed.), The psychology of learning and motivation: Advances in research and theory. New York: Academic Press. (8), 47-89.

Bavelier, D., Green, C. S., \& Seidenberg, M. S. (2013). Cognitive development: Gaming your way out of dyslexia? Current Biology, 23(7), R282-283. doi: 10.1016/j.cub.2013.02.051 
Beal-Alvarez, J. S., Lederberg, A. R., \& Easterbrooks, S. R. (2012). Grapheme-phoneme acquisition of deaf preschoolers. Journal of deaf studies and deaf education, 17(1), 39-60. doi: 10.1093/deafed/enr030

Bishop, D.V.M. (1997). Uncommon understanding: Development and disorders of language comprehension in children: Psychology press. First published by Psyhology Press, 27 Church Road, Hove, East Sussex. BN3 2FA. Simultaneously published in the USA and Canada.

Bitan, T., Manor, D., Morocz, I. A., \& Karni, A. (2005). Effects of alphabeticality, practice and type of instruction on reading an artificial script: An fMRI study. Cognitive Brain Research, 25(1), 90-106. doi: 10.1016/j.cogbrainres.2005.04.014

Bjaalid, I. K., Høien, T., \& Lundberg, I. (1997). Dual-route and connectionist models: A step towards a combined model. Scandinavian Journal of Psychology, 38(1), 73-82.

Bouton, S., Serniclaes, W., Bertoncini, J., \& Cole, P. (2012). Perception of speech features by French-speaking children with cochlear implants. Journal of Speech, Language, and Hearing research, 55(1), 139-153. doi: 10.1044/1092-4388(2011/10-0330)

Brem, S., Bach, S., Kucian, K., Guttorm, T. K., Martin, E., Lyytinen, H., Brandeis, D., \& Richardson, U. (2010). Brain sensitivity to print emerges when children learn letterspeech sound correspondences. PNAS, 107(17), 7939-7944. doi: 10.1073/pnas.0904402107

Byrne, B., Coventry, W. L., Olson, R. K., Samuelsson, S., Corley, R., Willcutt, E. G., Wadsworth, S., \& Defries, J. C. (2009). Genetic and Environmental Influences on Aspects of Literacy and Language in Early Childhood: Continuity and Change from Preschool to Grade 2. Journal of Neurolinguistics, 22(3), 219-236. doi: 10.1016/j.jneuroling.2008.09.003

Caravolas, M., Lervåg, A., Mousikou, P., Efrim, C., Litavsky, M., Onochie-Quintanilla, E., Salas, N., Schoffelova, M., Defior, S., Mikulajova, M., Seidlova-Malkova, G., \& Hulme, C. (2012). Common patterns of prediction of literacy development in different alphabetic orthographies. Psychological Science, 23(6), 678-686. doi: $10.1177 / 0956797611434536$

Castles, A., Coltheart., M, Larsen, L., Jones, P., Saunders, P., \& McArthur, G. (2009). Assessing the basic components of reading: A revision of the Castles and Coltheart 
test with new norms. Australian Journal of Learning Difficulties, 14(1), 67-88. doi: DOI: $10.1080 / 19404150902783435$

Clay, M. (1975). Early detection of reading difficulties: A diagnostic survey. Aukland, New Zealand: Heinemann.

Colin, S., Magnan, A., Ecalle, J., \& Leybaert, J. (2007). Relation between deaf children's phonological skills in kindergarten and word recognition performance in first grade. Journal of Child Psychology and Psychiatry, 48(2), 139-146. doi: 10.1111/j.14697610.2006.01700.x

Coltheart, M., Rastle, K., Perry, C., Langdon, R., \& Ziegler, J. (2001). DRC: A dual route cascaded model of visual word recognition and reading aloud. Psychological Review, 108(1), 204-256.

Easterbrooks, S. R., \& Beal-Alvarez, J. S. (2012). States' reading outcomes of students who are d/deaf and hard of hearing. American Annals of the Deaf, 157(1), 27-40.

Edwards, R. A. R. (2012). Words made flesh: Nineteenth-century deaf education and the growth of deaf culture. New York: New York University Press.

Foorman, B. R., \& Liberman, D. (1989). Visual and phonological processing of words: A comparison of good and poor readers. Journal of Learning Disability, 22(6), 349355.

Frith, U. (1985). Beneath the surface of developmental dyslexia. Developmental dyslexia, 13, 301-330.

Frylmark, A. (1995). Språkundersökning på BVC och hos logoped inför skolstart Stockholm: Socialstyrelsen, 96-144.

Gerken, L. A. (1994). Young children's representations of prosodic phonology: Evidence from English-speakers' weak syllable productions. Journal of Memory and Language, 33, 19-38.

Hatcher, P. J., Hulme, C., \& Snowling, M. J. (2004). Explicit phoneme training combined with phonic reading instruction helps young children at risk of reading failure. Journal of Child Psychology and Psychiatry, 45(2), 338-358.

Hellqvist, B. (1995). Lilla fonemtestet: Malmö, Pedagogisk Design, Sweden. 
Ibertsson, T., Hansson, K., Asker-Árnason, L., \& Sahlén, B. (2009). Speech recognition, working memory and conversation in children with cochlear implants. Deafness and Education International, 11(3), 132-151. doi: doi: 10.1002/dei.261

Just, M.A. \& Carpenter, P.A. (1992). A capacity theory of comprehension: Individual differences in working memory. Psychological Review, 99(1), 122-149.

Kamhi, A.G. \& Catts, H.W. (1986). Toward an understanding of developmental language and reading disorders. The Journal of Speech and Hearing disorder, 51(4), 337-347.

Kyle, F. E., \& Harris, M. (2010). Predictors of reading development in deaf children: A 3year longitudinal study. Journal of experimental child psychology, 107(3), 229-243. doi: 10.1016/j.jecp.2010.04.011

Kyle, F. E., \& Harris, M. (2011). Longitudinal patterns of emerging literacy in beginning deaf and hearing readers. Journal of Deaf Studies and Deaf Education, 16(3), 289304. doi: 10.1093/deafed/enq069

Kyle, F., Kujala, J., Richardson, U., Lyytinen, H., \& Goswami, U. (2013). Assessing the Effectiveness of Two Theoretically Motivated Computer-Assisted Reading Interventions in the United Kingdom: GG Rime and GG Phoneme. Reading Research Quarterly 48(1), 61-76 doi: doi:10.1002/rrq.038

Leonard, LB. (1998). Children with specific language impairment. Cambridge: MA: MIT Press.

Lervåg, A., Bråten, I., \& Hulme, C. (2009). The cognitive and linguistic foundations of early reading development: A Norwegian latent variable longitudinal study. Developmental Psychology, 45(3), 764-781. doi: 10.1037/a0014132

Lyxell, B., Sahlén, B., Wass, M., Ibertsson, T., Larsby, B., Hällgren, M., \& Mäki-Torkko, E. (2008). Cognitive development in children with cochlear implants: Relations to reading and communication. International Journal of Audiology, 47 Suppl 2, S4752. doi: 10.1080/14992020802307370

Lyytinen, H., Erskine, J., Kujala, J., Ojanen, E., \& Richardson, U. (2009). In search of a science-based application: A learning tool for reading acquisition. Scandinavian Journal of Psychology, 50(6), 668-675. doi: 10.1111/j.1467-9450.2009.00791.x

Lyytinen, H., Ronimus, M., Alanko, A., Poikkeus, A-M., \& Taanila, M. (2007). Early identification of dyslexia and the use of computer game-based practice to support 
reading acquisition. Nordic Psychology, 59(2), 109-126. doi: DOI - 10.1027/19012276.59.2.109

Marschark, M., Rhoten, C., \& Fabich, M. (2007). Effects of cochlear implants on children's reading and academic achievement. Journal of Deaf Studies and Deaf Education, 12(3), 269-282. doi: 10.1093/deafed/enm013

Marschark, M., Sarchet, T., Convertino, C. M., Borgna, G., Morrison, C., \& Remelt, S. (2012). Print exposure, reading habits, and reading achievement among deaf and hearing college students. Journal of Deaf Studies and Deaf Education, 17(1), 61-74. doi: 10.1093/deafed/enr044

McArthur, G., Eve, P. M., Jones, K., Banales, E., Kohnen, S., Anandakumar, T., Larsen, L., Marinus, E., Wang, H. C., \& Castles, A. (2012). Phonics training for Englishspeaking poor readers. Cochrane database of systematic reviews (Online), 12, CD009115. doi: 10.1002/14651858.CD009115.pub2

Melby-Lervåg, M., Lyster, S. A., \& Hulme, C. (2012). Phonological skills and their role in learning to read: A meta-analytic review. Psychological Bulletin, 138(2), 322-352. doi: $10.1037 / \mathrm{a} 0026744$

Moore, B. C. (2008). The role of temporal fine structure processing in pitch perception, masking, and speech perception for normal-hearing and hearing-impaired people. Journal of the Association for Research in Otolaryngology, 9(4), 399-406. doi: 10.1007/s10162-008-0143-x

Nakeva von Mentzer, C., Lyxell, B., Sahlén, B., Wass, M., Lindgren, M., Ors, M., Kallioinen, P., \& Uhlén, I. (2013). Computer-assisted training of phoneme-grapheme correspondence for children who are deaf and hard of hearing: Effects on phonological processing skills. International Journal of Pediatric Otorhinolaryngology, 77(12), 2049-2056. doi: 10.1016/j.ijporl.2013.10.007

Nation, K., Allen, R., \& Hulme, C. (2001). The limitations of orthographic analogy in early reading development: Performance on the clue-word task depends on phonological priming and elementary decoding skill, not the use of orthographic analogy. Journal of Experimental Child Psychology, 80(1), 75-94. doi: 10.1006/jecp.2000.2614

Nevo, E., \& Breznitz, Z. (2011). Assessment of working memory components at 6 years of age as predictors of reading achievements a year later. Journal of Experimental Child Psychology, 109(1), 73-90. doi: 10.1016/j.jecp.2010.09.010 
Powell, J., \& Wilson, J.A. (2011). The impact of CI on deaf education. Clinical Otolaryngology (36), 417-418.

Power, D., \& Leigh, G. R. (2000). Principles and Practices of Literacy Development for Deaf Learners: A Historical Overview. Journal of Deaf Studies and Deaf Education, $5(1), 3-8$.

Rastle, K. (2007). Visual word recognition, in The Oxford Handbook of Psycholinguistics (M. G. Gaskell Ed.), chapter 5, 71-87. Oxford University Press Inc., New York: Oxford University Press.

Raven, J.C. (1995). Raven's matrices-Coloured. J C Raven Ltd Oxford Psychologists Press. Repovš, G., \& Baddeley, A. (2006). The multi-component model of working memory: Explorations in experimental cognitive psychology. Neuroscience, 139, 5-21.

Sahlén, B., Reuterskiöld-Wagner, C. , Nettelbladt, U. , \& Radeborg, K. (1999). Non-word repetition in children with language impairment--pitfalls and possibilities. International Journal of Language \& Communication Disorders, 34(3), 337-352.

Saine, N. L., Lerkkanen, M. K., Ahonen, T., Tolvanen, A., \& Lyytinen, H. (2011). Computer-assisted remedial reading intervention for school beginners at risk for reading disability. Child Development, 82(3), 1013-1028. doi: 10.1111/j.14678624.2011.01580.x

Share, D. L. (1995). Phonological recoding and self-teaching: Sine qua non of reading acquisition. Cognition, 55(2), 151-218.

Specialpedagogic Center, Vasa. (2006-2008). ABC- läs och skrivutvecklingsprojekt. Available from: www.vasa.abo.fi/speccenter/forskning_och_projekt.htm 2014-0613

Torgesen, J., Wagner, R., \& Rashotte, CA. (1999). A Test of Word Reading Efficiency (TOWRE). PRO-ED; Austin, Texas.

Traxler, C. B. (2000). The Stanford Achievement Test, 9th Edition: National Norming and Performance Standards for Deaf and Hard-of-Hearing Students. Journal of Deaf Studies and Deaf Education, 5(4), 337-348. doi: 10.1093/deafed/5.4.337

Trezek, B. J., \& Malmgren, K. W. (2005). The efficacy of utilizing a phonics treatment package with middle school deaf and hard-of-hearing students. Journal of Deaf Studies and Deaf Education, 10(3), 256-271. doi: 10.1093/deafed/eni028 
Wass, M., Ibertsson, T., Lyxell, B., Sahlén, B., Hällgren, M., Larsby, B., \& Mäki-Torkko, E. (2008). Cognitive and linguistic skills in Swedish children with cochlear implants - measures of accuracy and latency as indicators of development. Scandinavian Journal of Psychology, 49(6), 559-576. doi: 10.1111/j.1467-9450.2008.00680.x

Wass, M., Lyxell, B., Sahlén, B., Asker-Arnason, L., Ibertsson, T., Mäki-Torkko, E., Hallgren, M., \& Larsby, B. (2010). Cognitive skills and reading ability in children with cochlear implants. Cochlear Implants International, 11 Suppl 1, 395-398. doi: 10.1179/146701010X12671178103751

Woodcock, RW. (1987). Woodcock Reading Mastery Test-Revised. Circle Pines, MN.: American Guidance Service.

Woodhouse, L., Hickson, L., \& Dodd, B. (2009). Review of visual speech perception by hearing and hearing-impaired people: Clinical implications. International Journal of Language and Communication Disorders, 44(3), 253-270. doi: $10.1080 / 13682820802090281$ 